\title{
BMJ Open Risk of adverse pregnancy outcomes associated with short and long birth intervals in Bangladesh: evidence from six Bangladesh Demographic and Health Surveys, 1996-2014
}

Monjura Khatun Nisha, ${ }^{1}$ Ashraful Alam, ${ }^{1}$ Mohammad Tajul Islam, ${ }^{2}$ Tanvir Huda, ${ }^{1}$ Camille Raynes-Greenow ${ }^{1}$

To cite: Nisha MK, Alam A, Islam MT, et al. Risk of adverse pregnancy outcomes associated with short and long birth intervals in Bangladesh: evidence from six Bangladesh Demographic and Health Surveys, 1996-2014. BMJ Open 2019;9:e024392. doi:10.1136/ bmjopen-2018-024392

\section{- Prepublication history for} this paper is available online. To view these files, please visit the journal online (http://dx.doi. org/10.1136/bmjopen-2018024392).

Received 25 May 2018 Revised 13 November 2018 Accepted 12 December 2018

D) Check for updates

(c) Author(s) (or their employer(s)) 2019. Re-use permitted under CC BY-NC. No commercial re-use. See rights and permissions. Published by BMJ.

${ }^{1}$ Sydney School of Public Health, The University of Sydney, Sydney, New South Wales, Australia

${ }^{2}$ Save the Children Bangladesh, Dhaka, Bangladesh

Correspondence to

Monjura Khatun Nisha;

mnis2091@uni.sydney.edu.au

\section{ABSTRACT}

Objective To examine the effect of short ( $<36$ months) and long ( $\geq 60$ months) birth intervals on adverse pregnancy outcomes in Bangladesh.

Design, setting and participants We analysed data from six Bangladesh Demographic and Health Surveys (19961997, 1999-2000, 2004, 2007, 2011 and 2014). We included all singleton non-first live births, most recently born to mothers within 5 years preceding each survey $(n=21382)$. We defined birth interval according to previous research which suggests that a birth interval between 36 and 59 months is the most ideal interval. Bivariate and multivariable analyses were conducted to obtain the crude and adjusted ORs (aOR) respectively to assess the odds of first-day neonatal death, early neonatal death and small birth size for both short ( $<36$ months) and long ( $\geq 60$ months) spacing between births.

Main outcome measures First-day neonatal death, early neonatal death and small birth size.

Results In the multivariable analysis, compared with births spaced 36-59 months, infants with a birth interval of $<36$ months had increased odds of first-day neonatal death (a0R: $2.11,95 \% \mathrm{Cl}: 1.17$ to 3.78 ) and early neonatal death (aOR: $1.58,95 \% \mathrm{Cl}: 1.13$ to 2.22). Compared with births spaced 36-59 months, infants with a birth interval of $\geq 60$ months had increased odds of first-day neonatal death (aOR: $2.02,95 \% \mathrm{Cl}: 1.10$ to 3.73 ) and small birth size (aOR: $1.17,95 \% \mathrm{Cl}: 1.02$ to 1.34). When there was a history of any previous pregnancy loss, there was an increase in the odds of first-day and early neonatal death for both short and long birth intervals, although it was not significant.

Conclusions Birth intervals shorter than 36 months and longer than 59 months are associated with increased odds of adverse pregnancy outcomes. Care-providers, programme managers and policymakers could focus on promoting an optimal birth interval between 36 and 59 months in postpartum family planning.

\section{BACKGROUND}

Adverse pregnancy outcomes such as stillbirth, early neonatal mortality and low birthweight
Strengths and limitations of this study

- The main strength of this study is the use of a large sample from six nationally representative surveys of Bangladesh with a very high response $(98 \%)$.

- We used data from most recent births within the 5 years preceding the surveys in order to minimise recall bias.

Our study is the first in Bangladesh which analysed the effect of birth intervals and other risk factors for first-day neonatal mortality.

- Demographic and Health Survey data is cross-sectional, which reduces the ability to infer causation.

- Demographic and Health Survey data uses maternal perception of infant birth size as a proxy for birthweight which may be a limitation.

are of considerable public health significance. Globally, perinatal mortality (stillbirth and early neonatal mortality) accounts for $>5$ million deaths every year. ${ }^{12}$ Of those deaths, approximately 2 million occur in the early neonatal period. ${ }^{3}$ The risk is greatest on the first day of birth, approximately 1 million newborns die within the first 24hours. ${ }^{3}$ Furthermore, low birthweight occurs in $>20$ million newborns worldwide, which is a major contributor to perinatal mortality and up to $80 \%$ of neonatal mortality. ${ }^{4}$ The greatest proportion of perinatal deaths and low birthweight (97\%-99\%) occur in low-and middle-income countries (LMICs). ${ }^{5}$

Several interventions have been suggested to address adverse pregnancy outcomes, such as pregnancy spacing. ${ }^{6}$ Both short and long birth intervals have been reported to be associated with an increased risk of a number of adverse perinatal outcomes. ${ }^{78}$ Current World Health Organization (WHO) guidelines recommend an interval of at least 
24 months before attempting the next pregnancy after a live birth (ie, birth-to-pregnancy interval) in order to reduce any adverse pregnancy outcomes. ${ }^{9}$ Thus, the birth-to-birth interval should be at least 33 months by including 9 months of pregnancy to the recommended 24 months. ${ }^{10}$ In an analysis of Demographic and Health Survey (DHS) data from 17 LMICs, Rutstein suggested that the optimal birth interval should be between 36 and 59 months as birth intervals $<36$ and $>59$ months showed a tendency towards neonatal mortality and morbidity. ${ }^{11}$ The WHO highlighted the necessity of future research investigating the association between birth interval and adverse pregnancy outcomes. ${ }^{9}$

Bangladesh has a high perinatal mortality (44 per 1000 pregnancies) and morbidity, ${ }^{12}$ where birth spacing remains a problem. ${ }^{13}$ Between the year 1993 and 2014, although the median birth interval increased by $49 \%$ (from 35 to 52 months), approximately $30 \%$ of non-first births occurred within $<36$ months (7-35 months) following the previous birth. ${ }^{12}$ However, another $40 \%$ of non-first births occurred following a birth interval of $>59$ months. ${ }^{12}$ Of the papers investigating birth interval in Bangladesh, most have focused on the effect of a short birth interval and have not considered a long birth interval as a risk of adverse perinatal outcome. ${ }^{1415}$ Given the changing demographics in Bangladesh and an increase in the proportion of longer birth intervals, our objective was to examine whether the preceding birth interval (short or long) was independently associated with an increased risk of adverse pregnancy outcomes including first-day neonatal mortality, early neonatal mortality and low birthweight, using pooled data from the Bangladesh Demographic and Health Surveys (BDHS).

\section{METHODS}

\section{Data source}

We used the BDHS data from the years: 1996-1997, 1999-2000, 2004, 2007, 2011 and 2014. BDHS is a nationally representative household survey carried out every 3-4years under the authority of the National Institute of Population Research and Training of the Ministry of Health and Family Welfare. The survey employed a two-stage stratified cluster-sampling design with rural and urban samples to collect information from ever-married women aged 15-49 years and ever-married men 15-54 years about demographic and health status. Data were obtained from the website: www.measuredhs.com. The BDHS consists of three types of questionnaires: household, women and men. Our analysis was limited to the information obtained from the women's and household questionnaires. We pooled the data files from six surveys and analysed the live births occurring during the 5 years preceding the surveys. The DHS programme employs standardised data collection procedures with model questionnaires to ensure consistent content over time and across countries allowing comparability across populations cross-sectionally and over time. ${ }^{16}$ We selected six recent surveys in this pooled analysis based on the similarities in sampling design, comparability of survey questionnaires for focus variables of this analysis and availability of data for the pooled analysis. In our analysis, we included the data from all singleton, non-first, most recent liveborn children within the 5 years preceding the six BDHS, 1996-1997, 1999-2000, 2004, 2007, 2011 and 2014.

\section{Outcome variables}

We conducted three analyses, with three different outcome variables-'first-day neonatal death', 'early neonatal death' and 'small birth size'. First-day deaths were defined as deaths during the first 24 hours after birth (day ' 0 ') among live-born children, and early neonatal deaths were deaths between the age of 0 and 6 days among live-born children. These two outcome variables overlap, but conform to standard definitions. We used 'small birth size' as a proxy for low birthweight. Estimates of birthweight are not collected by the BDHS. 'Mother's perception of the infant's birth size is routinely used as a proxy indicator of birthweight. For our analysis, we defined 'small birth size' as the birth size of an infant which was perceived as either 'very small' or 'smaller than average'. Each of the outcome variables was considered dichotomous for this analysis as yes (1) or no (0).

\section{Exposure variable}

The main exposure variable used in our analysis was the length of the preceding birth interval as a measure of birth spacing. This was measured as the number of months between two successive live births. ${ }^{11}{ }^{17} \mathrm{We}$ followed Rutstein's recommendation regarding optimal birth interval of 36-59 months for our analysis. ${ }^{11}$ We categorised the preceding birth interval in months as short ( $<36$ months) or long ( $\geq 60$ months) birth intervals for our analysis, where the birth interval of 36-59 months was the reference category.

\section{Covariates}

Covariates included maternal age at childbirth (19 years or below, 20-34 years and 35 years or more), maternal education (none, primary and secondary or higher), birth order $(2-3, \geq 4)$, maternal body mass index (BMI) (underweight, average, overweight and obese), area of residence (urban and rural), wealth index (poorest quintile, second quintile, middle quintile, fourth quintile and richest quintile), maternal employment status during survey (currently working and not working), maternal desire of pregnancy (yes and no), ever use of contraception (yes and no), number of antenatal care (ANC) visits (none, $1-3$ visits and $\geq 4$ visits), ANC by skilled birth attendants (SBA) (yes and no), history of any previous loss of pregnancy (yes and no), sex of baby (female and male) and region (Dhaka, Barisal, Chittagong, Khulna, Rajshahi, Rangpur and Sylhet).

We constructed the 'wealth index' variable using principal component analysis through ranking the available wealth variables in the pooled BDHS dataset such 
as, housing materials, type of toilet facility, source of drinking water, type of cooking fuel, availability of electricity and ownership of assets (radio, television, fridge, etc), adjusted for urban-rural differences. We constructed the 'ever use of contraception' variable from calendar data of women's dataset for each year, where 'ever use of contraception' was recorded if there was any contraceptive practice at anytime.

\section{Data analysis}

The 'first-day neonatal mortality' and 'early neonatal mortality' variables were calculated from the birth history data, where age at death was recorded in days if they were aged $<30$ days. 'Small birth size' was calculated from the birth history data, based on the perceptions of mothers about their infant's birth size. Frequencies with weighted percentage were calculated for the selected variables to describe the characteristics of the women who had a 'first-day neonatal death', an 'early neonatal death' and a 'small birth size' infant. We conducted bivariate analysis to ascertain the unadjusted association between each of the independent variables and each outcome separately, and multivariable analysis was performed to obtain the adjusted OR (aOR). All covariates associated with the outcomes at $\mathrm{p} \leq 0.25$ in the unadjusted analysis were included in the final multivariable logistic regression model. Furthermore, several other covariates (maternal education, maternal wealth status, maternal area of residence, maternal desire of pregnancy, number of ANC and ANC by SBA) were included in the final model regardless of their significant levels because they are known risk factors of adverse pregnancy outcomes. ${ }^{118-20}$ The 'year of survey' was not included in our final model as the p-value between 'year of survey' and each of the outcome variables was $>0.25$ in the unadjusted analysis. However, to test the effect of 'year of survey' we repeated the model and included 'year of survey'. This made no difference to the findings (results not shown), and hence, we kept the original model. We also checked the variables for multicollinearity. The Wald test was used to assess statistical significance with a $95 \%$ confidence interval (CI). The association was adjusted for potential confounders including maternal age at childbirth, birth order, maternal

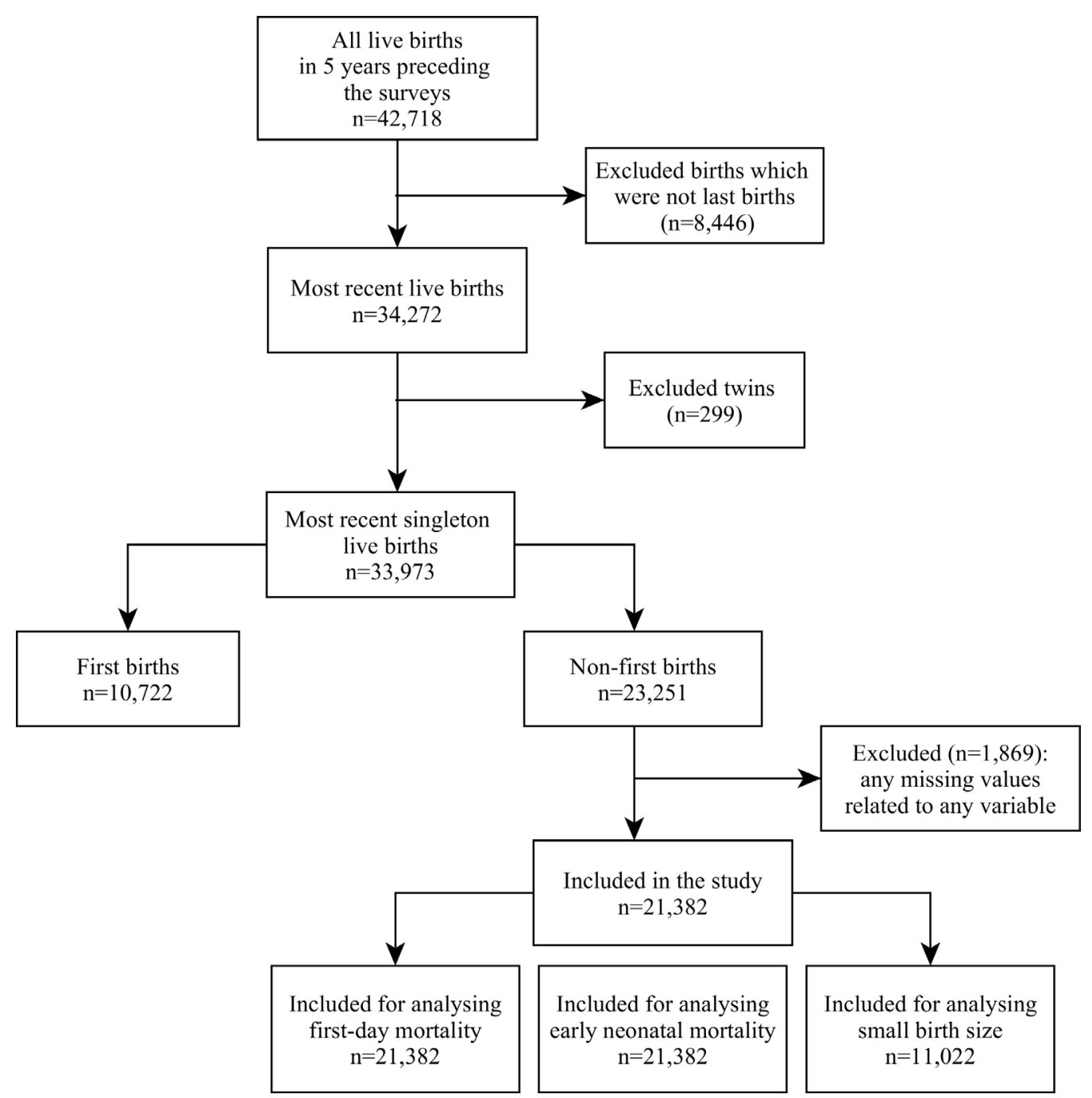

Figure 1 Flow diagram showing sample selection for first-day neonatal mortality, early neonatal mortality and small birth size analysis. 


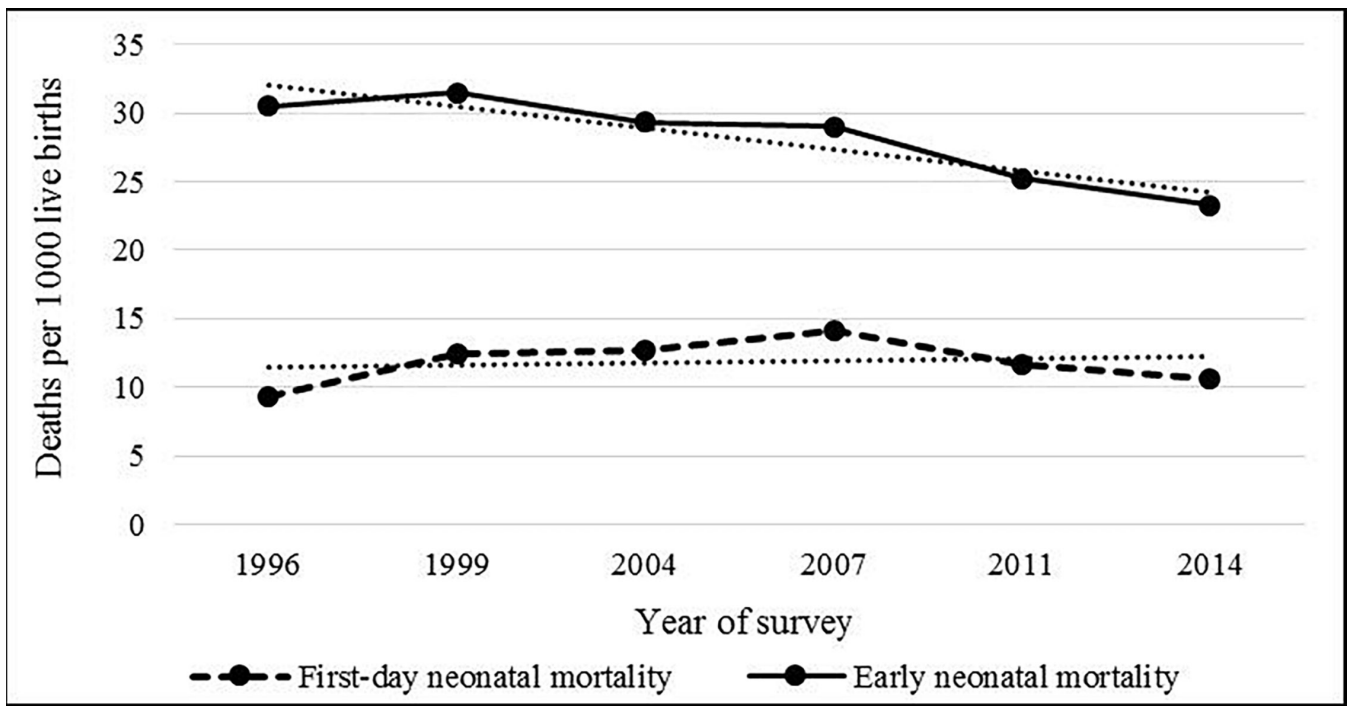

Figure 2 Trends in first-day and early neonatal mortality by year of survey (1996-2014).

education, maternal wealth index, maternal employment status, area of residence, maternal BMI, maternal desire of pregnancy, ever use of contraceptive method, number of ANC visits, ANC by SBA, history of any previous pregnancy loss, sex of infant and region.

We further restricted our analysis by 'history of any previous pregnancy loss' to assess the combined effect of history of any previous pregnancy loss and birth interval (short or long) on all three outcomes. We followed the direct life table approach to calculate first-day and early neonatal mortality rates per 1000 live births. All analyses were carried out using STATA V.14.2. We used the 'svy' command in all our analyses to calculate the weighted values in order to adjust for the clustering effect and sample stratification.
We obtained permission from Monitoring and Evaluation to Assess and Use Results Demographic and Health Surveys to download the data from the DHS online archive.

\section{Patient involvement}

No patients were involved in this study.

\section{RESULTS}

Over the six surveys, and approximately 18 years of data, a total of 42718 live births were recorded who were born to mothers aged 15-49 years within the 5 years preceding the surveys with a high response (approximately 98\%) (figure 1). From the years 1996 to 2014, there was a

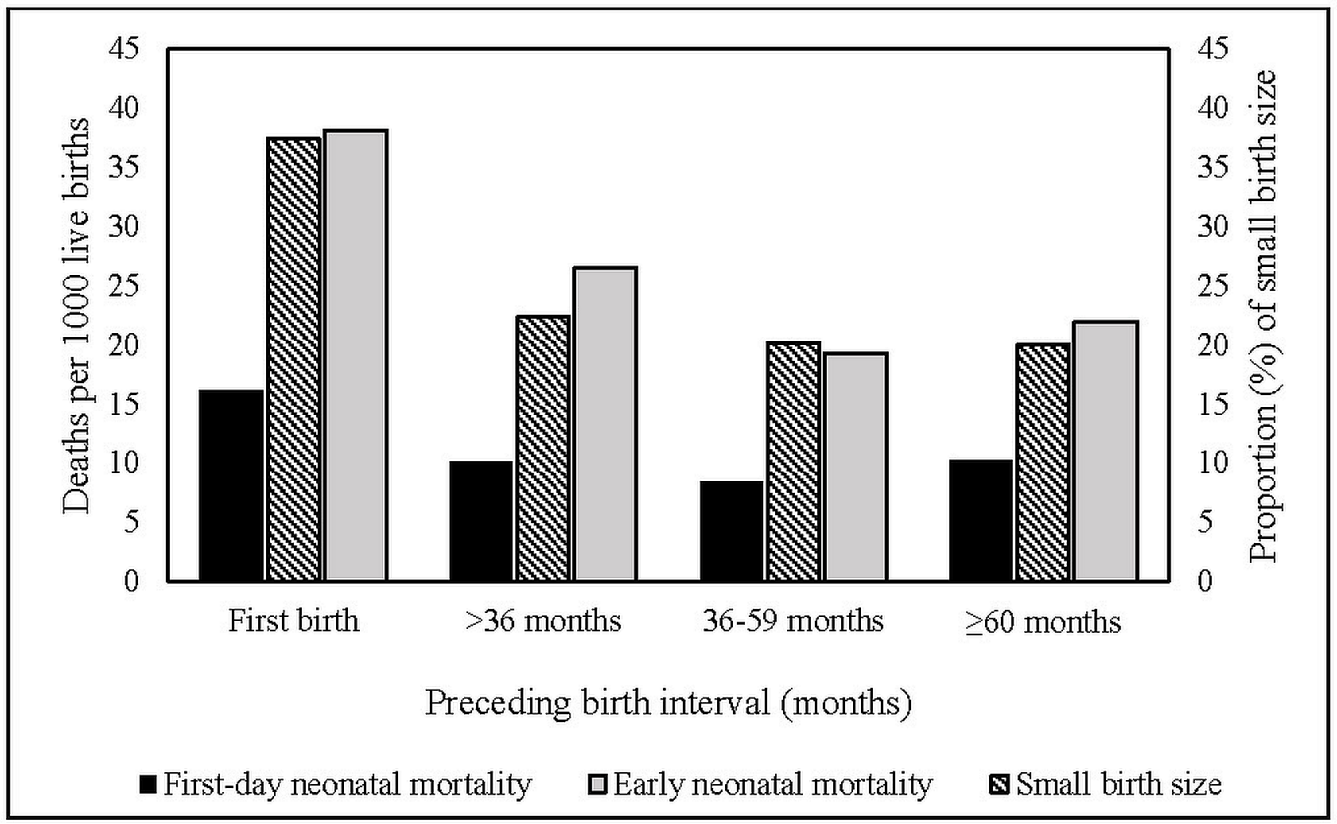

Figure 3 First-day neonatal mortality, early neonatal mortality rates per 1000 live births and the proportion of small birth size by preceding birth intervals. 
substantial decrease in the rate of overall early neonatal mortality (30.5 vs 23.3 deaths per 1000 live births), but in terms of first-day neonatal mortality, we did not find any consistent decrease, rather the rate has increased from 9.3 deaths in 1996 to 10.6 deaths in 2014 per 1000 live births (figure 2). Rates of all three adverse pregnancy outcomes were highest among the first-born infants followed by the infants whose births were spaced $<36$ months (figure 3 ).

There were 33973 singleton live-born infants, most recently born to mothers within the 5 years preceding each survey. Of those, 10722 (32\%) were first-born infants who were ineligible as there was no birth interval, which left 21382 non-first singleton live-born infants in our final analysis for first-day and early neonatal mortality. For small birth size, our analysis consisted of 11022 singleton live-born infants only, for the years 1999-2000, 2011 and 2014, as the data regarding birth size were not available for the surveys in 1996-1997, 2004 and 2007 (figure 1).

Of the 21382 non-first singleton most recently liveborn infants of six surveys, there were 115 first-day and 274 early neonatal deaths. Of 11022 non-first singleton most recently live-born infants of three surveys, there were 2002 infants with a birth size smaller than average.

\section{First-day neonatal mortality}

Nearly half of the infants who died on day ' 0 ' $(n=49)$ were born following a short birth interval, another 44 infants who died on day ' 0 ' (36.0\%) were born following a long birth interval. Overall, a greater proportion of mothers of the infants who died on day ' 0 ' aged between 20 and 34 years $(\mathrm{n}=82,67.5 \%)$, did not have any formal education $(\mathrm{n}=40,36.4 \%)$, had a parity $2-3(\mathrm{n}=73,63.3 \%)$, had an average BMI $(\mathrm{n}=67,59.2 \%)$ and lived in a rural area $(\mathrm{n}=80,79.2 \%)$ (table 1$)$.

\section{Early neonatal mortality}

A large proportion of deaths in the early neonatal period were attributable to day ' 0 ' deaths $(\mathrm{n}=115,42.8 \%)$. Approximately $45 \%$ of infants $(n=122)$ who died within 7 days of birth were born following a short birth interval. Furthermore, a relatively higher proportion (29\% vs $26 \%$ ) of early neonatal deaths had a long birth interval compared with the recommended birth interval (36-59 months). The sociodemographic characteristics of mothers of the infants who died in the early neonatal period were quite similar to the day ' 0 ' findings, and the proportion of early neonatal mortality was highest among infants born to mothers aged $20-34$ years $(n=200,71.5 \%)$, had a parity $2-3(n=163,60.0 \%)$, did not have any formal education $(n=116,42.0 \%)$, lived in a rural area $(n=193$, $81.0 \%)$, had an average BMI $(\mathrm{n}=156,58.4 \%)$ and did not receive any ANC ( $\mathrm{n}=146,55.2 \%)$ (table 1$)$.

\section{Small birth size}

More than one-third of infants with a small birth size $(\mathrm{n}=698,34.6 \%)$ were born with a short birth interval. A similar proportion of infants with a small birth size $(\mathrm{n}=694,34.2 \%)$ were born with a long birth interval. The highest proportion of infants with a small birth size were born to mothers aged $20-34$ years $(n=1599,80.0 \%)$, had a parity $2-3(\mathrm{n}=1322,65.8 \%)$, had no formal education $(\mathrm{n}=751,38.3 \%)$, had an average BMI $(\mathrm{n}=1069,54.5 \%)$, lived in a rural area $(\mathrm{n}=1445,79.9 \%)$ and did not receive any ANC ( $\mathrm{n}=998,51.4 \%)$ (table 1$)$.

Association of birth intervals with first-day neonatal mortality In the multivariable analysis, both short and long birth intervals were associated with increased odds of first-day neonatal death. Compared with infants born following a birth interval of 36-59 months, infants with a short birth interval were 2.11 times more likely to die within 24 hours of birth (95\% CI: 1.17 to 3.78). We also found that infants born after a long birth interval, compared with those born following a birth interval of 36-59 months had two times higher odds of dying within 24 hours of birth $(95 \% \mathrm{CI}$ : 1.10 to 3.73 ) (table 2).

\section{Association of birth intervals with early neonatal mortality}

After adjustment for potential confounders, early neonatal mortality was associated with a short birth interval, while for long birth intervals, no significant association was found. Compared with infants with a birth interval of 36-59 months, infants born with a short birth interval had 1.58 times higher odds of dying within 7 days of birth (95\% CI: 1.13 to 2.22). Although the odds of early neonatal mortality were greater for long birth intervals compared with the reference group, there was no significant association (aOR: $1.23,95 \%$ CI: 0.84 to 1.81 ) (table 2).

\section{Association of birth intervals with small birth size}

Long birth intervals appeared to be associated with increased odds of small birth size compared with the reference birth interval (aOR: 1.17, 95\% CI: 1.02 to 1.34), while for short birth intervals, the odds of small birth size were smaller (aOR: 1.04, 95\% CI: 0.90 to 1.20 ) compared with the reference birth interval (table 2).

A history of pregnancy loss can be a determinant of birth interval and we therefore restricted our analysis to the infants whose mothers had a history of any previous pregnancy loss for all three outcomes. However, we found no significant relationship for either short or long birth intervals with all three outcomes, although for both short and long birth intervals, there was an increase in the odds for first-day and early neonatal death (table 3 ).

\section{DISCUSSION}

This study suggests that both short and long birth intervals were associated with adverse pregnancy outcomes. Over the six surveys, a major proportion of infants who died on the first day, or in the first week or with a small birth size were born before the recommended optimal birth interval (36-59 months). We found that a birth-tobirth interval $<36$ months was associated with increased odds of multiple adverse pregnancy outcomes including 
Table 1 First-day neonatal mortality, early neonatal mortality and small birth size infants by maternal characteristics in Bangladesh: BDHS 1996-2014

\begin{tabular}{|c|c|c|c|}
\hline & $\begin{array}{l}\text { First-day neonatal mortality } \\
(n=21382) \\
n(\%)\end{array}$ & $\begin{array}{l}\text { Early neonatal mortality } \\
(n=21382) \\
n(\%)\end{array}$ & $\begin{array}{l}\text { Small birth size } \\
(\mathrm{n}=11022) \\
\mathrm{n}(\%)\end{array}$ \\
\hline Predictors & $\mathrm{n}=115$ & $\mathrm{n}=274$ & $\mathrm{n}=2002$ \\
\hline \multicolumn{4}{|c|}{ Preceding birth interval in months } \\
\hline$<36$ & $49(45.2)$ & $122(45.2)$ & $698(34.6)$ \\
\hline $36-59$ & $22(18.8)$ & $70(26.2)$ & $610(31.2)$ \\
\hline$\geq 60$ & $44(36.0)$ & $82(28.6)$ & $694(34.2)$ \\
\hline \multicolumn{4}{|c|}{ Mother's age at childbirth (years) } \\
\hline$\leq 19$ & $20(21.1)$ & $40(16.2)$ & $218(10.7)$ \\
\hline $20-34$ & $82(67.5)$ & $200(71.5)$ & $1599(80.0)$ \\
\hline$\geq 35$ & $13(11.4)$ & $34(12.3)$ & $185(9.3)$ \\
\hline \multicolumn{4}{|l|}{ Birth order } \\
\hline $2-3$ & $73(63.3)$ & $163(60.0)$ & $1322(65.8)$ \\
\hline$\geq 4$ & $42(36.7)$ & $111(40.0)$ & $680(34.2)$ \\
\hline \multicolumn{4}{|l|}{ Maternal education } \\
\hline None & $40(36.4)$ & $116(42.0)$ & $751(38.3)$ \\
\hline Primary & $41(33.7)$ & $84(30.6)$ & $618(29.0)$ \\
\hline Secondary or higher & $34(29.9)$ & $74(27.4)$ & $633(32.7)$ \\
\hline \multicolumn{4}{|l|}{ Wealth index } \\
\hline Poorest quintile & $24(19.6)$ & $71(23.5)$ & $428(19.6)$ \\
\hline Second quintile & $24(21.6)$ & $63(24.0)$ & $394(19.8)$ \\
\hline Middle quintile & $24(19.5)$ & $57(22.2)$ & $389(19.4)$ \\
\hline Fourth quintile & $20(20.2)$ & $35(13.5)$ & $388(20.7)$ \\
\hline Richest quintile & $23(19.1)$ & $48(16.8)$ & $403(20.5)$ \\
\hline \multicolumn{4}{|l|}{ Employment status } \\
\hline Currently working & $34(32.1)$ & $70(28.0)$ & $339(18.0)$ \\
\hline Not working & $81(67.9)$ & $204(72.0)$ & $1663(82.0)$ \\
\hline \multicolumn{4}{|l|}{ Area of residence } \\
\hline Urban & $35(20.8)$ & $81(19.0)$ & $557(20.1)$ \\
\hline Rural & $80(79.2)$ & $193(81.0)$ & 1445 (79.9) \\
\hline \multicolumn{4}{|l|}{ Maternal BMI } \\
\hline Underweight & $27(23.1)$ & $83(29.3)$ & 711 (35.3) \\
\hline Average & $67(59.2)$ & $156(58.4)$ & 1069 (54.5) \\
\hline Overweight & $16(13.1)$ & $26(9.3)$ & $169(7.9)$ \\
\hline Obese & $5(4.6)$ & $9(3.0)$ & $53(2.3)$ \\
\hline \multicolumn{4}{|c|}{ Maternal desire of pregnancy } \\
\hline Yes & 77 (63.3) & $171(63.5)$ & $1205(60.1)$ \\
\hline No & $38(36.7)$ & $103(36.5)$ & 797 (39.9) \\
\hline \multicolumn{4}{|l|}{ Ever use of contraception } \\
\hline Yes & $81(72.9)$ & $196(71.9)$ & $1605(81.1)$ \\
\hline No & $34(27.1)$ & $78(28.1)$ & $397(18.9)$ \\
\hline \multicolumn{4}{|l|}{ No. of ANC visits } \\
\hline None & $48(43.1)$ & $146(55.2)$ & $998(51.4)$ \\
\hline $1-3$ & $46(40.7)$ & $90(32.0)$ & $683(33.7)$ \\
\hline$\geq 4$ & $21(16.2)$ & $38(12.8)$ & $321(14.9)$ \\
\hline
\end{tabular}


Table 1 Continued

\begin{tabular}{|c|c|c|c|}
\hline & $\begin{array}{l}\text { First-day neonatal mortality } \\
(n=21382) \\
n(\%)\end{array}$ & $\begin{array}{l}\text { Early neonatal mortality } \\
(n=21382) \\
n(\%)\end{array}$ & $\begin{array}{l}\text { Small birth size } \\
(n=11022) \\
n(\%)\end{array}$ \\
\hline Predictors & $n=115$ & $n=274$ & $\mathrm{n}=2002$ \\
\hline \multicolumn{4}{|l|}{ ANC by SBA } \\
\hline Yes & $56(47.3)$ & $111(38.6)$ & $817(38.8)$ \\
\hline No & $59(52.7)$ & $163(61.4)$ & $1185(61.2)$ \\
\hline \multicolumn{4}{|c|}{ History of any previous pregnancy loss } \\
\hline Yes & 35 (26.3) & 79 (26.2) & 435 (21.4) \\
\hline No & $80(73.7)$ & 195 (73.8) & 1567 (78.6) \\
\hline \multicolumn{4}{|l|}{ Sex of infant } \\
\hline Male & $74(64.1)$ & $162(58.0)$ & 943 (44.9) \\
\hline Female & 41 (35.9) & $112(42.0)$ & $1059(55.1)$ \\
\hline \multicolumn{4}{|l|}{ Region } \\
\hline Barisal & $10(4.2)$ & $28(5.5)$ & $176(4.7)$ \\
\hline Chittagong & $12(10.1)$ & 40 (13.9) & 463 (25.4) \\
\hline Khulna & $10(8.2)$ & $27(9.0)$ & 232 (8.6) \\
\hline Rajshahi & $27(25.1)$ & $50(20.9)$ & 227 (13.2) \\
\hline Rangpur & $15(8.0)$ & $47(10.7)$ & 235 (8.2) \\
\hline Sylhet & $10(3.5)$ & $18(3.5)$ & $281(7.1)$ \\
\hline Dhaka & $31(40.9)$ & 64 (36.5) & $388(32.8)$ \\
\hline \multicolumn{4}{|l|}{ Year of survey } \\
\hline 1996 & $16(14.0)$ & $45(15.8)$ & - \\
\hline 1999 & $13(10.7)$ & $45(15.8)$ & 705 (34.2) \\
\hline 2004 & $22(20.1)$ & 55 (21.2) & - \\
\hline 2007 & 19 (17.9) & 37 (13.6) & - \\
\hline 2011 & $29(24.1)$ & $59(21.5)$ & $813(40.1)$ \\
\hline 2014 & $16(13.2)$ & $33(12.1)$ & $484(25.7)$ \\
\hline
\end{tabular}

ANC, antenatal care; BDHS, Bangladesh Demographic and Health Surveys; BMI, body mass index; SBA, skilled birth attendants.

first-day neonatal mortality and early neonatal mortality. Also, a birth-to-birth interval $>59$ months was associated with increased odds of first-day neonatal mortality and small birth size.

Infants born with a short birth-to-birth interval of $<36$ months had higher odds of first-day neonatal mortality. Several studies have reported an association of a short birth interval with perinatal or neonatal mortality. ${ }^{21}{ }^{22}$ However, to the best of our knowledge, no prior research has examined the effect of birth interval on first-day neonatal mortality individually. Furthermore, we found that the odds of early neonatal mortality were also greater among infants who were born following a short birth interval. This is consistent with findings of previous investigations from other LMICs which examined the effect of short birth intervals on perinatal, early neonatal or neonatal mortality. ${ }^{21}{ }^{22}$ Similar to our findings, a previous study conducted in India reported an association of neonatal death with a birth interval of $<36$ months (aOR: $1.78,95 \%$ CI: 1.63 to 1.94 ), compared with births spaced 36-59 months. ${ }^{22}$ Again, an analysis of 47 DHS also supports our finding of higher odds of early neonatal mortality for short birth intervals, although this analysis has used slightly different definitions of both the short birth interval ( $<24$ months) and the reference category (24 to $<60$ months). ${ }^{23}$ Furthermore, our finding is in line with the finding of a previous study conducted in Matlab, Bangladesh, where they reported an increased risk of very short birth intervals ( $<15$ months) on early neonatal mortality compared with those born after 36-59 months, although in their study the risk of early neonatal mortality goes down as the birth interval increases up to a minimum of 24-59 months, which is not consistent with our findings. ${ }^{14}$ Furthermore, we did not find any significant association between short birth interval and small birth size, although infants born following a short interval were at increased odds of being born with a small birth size. In BDHS, birthweight is not routinely collected and birth size is based on maternal perception of infant birth size, which could lead to errors in the estimation of small 
Table 2 Results of multivariable analysis for the association between preceding birth intervals and adverse pregnancy outcomes in Bangladesh: BDHS 1996-2014

\begin{tabular}{|c|c|c|c|c|c|c|}
\hline \multirow[b]{2}{*}{ Predictors } & \multicolumn{2}{|c|}{$\begin{array}{l}\text { First-day neonatal mortality } \\
n=21382\end{array}$} & \multicolumn{2}{|c|}{$\begin{array}{l}\text { Early neonatal mortality } \\
\mathrm{n}=21382\end{array}$} & \multicolumn{2}{|l|}{$\begin{array}{l}\text { Small birth size } \\
\mathrm{n}=11022\end{array}$} \\
\hline & aOR $(95 \% \mathrm{Cl})$ & $P$ value & aOR $(95 \% \mathrm{Cl})$ & $P$ value & aOR $(95 \% \mathrm{Cl})$ & $P$ value \\
\hline \multicolumn{7}{|c|}{ Preceding birth interval in months } \\
\hline$<36$ & 2.11 (1.17 to 3.78$)$ & $<0.05$ & 1.58 (1.13 to 2.22$)$ & $<0.05$ & 1.04 (0.90 to 1.20$)$ & 0.08 \\
\hline $36-59$ & Reference & & Reference & & Reference & \\
\hline$\geq 60$ & 2.02 (1.10 to 3.73$)$ & & $1.23(0.84$ to 1.81$)$ & & $1.17(1.02$ to 1.34$)$ & \\
\hline \multicolumn{7}{|c|}{ Mother's age at childbirth (years) } \\
\hline$\leq 19$ & 2.51 (1.35 to 4.66$)$ & $<0.05$ & 1.53 (1.02 to 2.28$)$ & $<0.05$ & $1.01(0.83$ to 1.21$)$ & 0.68 \\
\hline 20-34 & Reference & & Reference & & Reference & \\
\hline$\geq 35$ & 1.34 (0.67 to 2.69) & & 1.46 (0.93 to 2.29$)$ & & $1.10(0.89$ to 1.36$)$ & \\
\hline \multicolumn{7}{|l|}{ Birth order } \\
\hline $2-3$ & Reference & & Reference & & Reference & \\
\hline$\geq 4$ & $1.48(0.88$ to 2.50$)$ & 0.14 & 1.27 (0.92 to 1.75$)$ & 0.15 & $1.02(0.89$ to 1.16$)$ & 0.81 \\
\hline \multicolumn{7}{|l|}{ Maternal education } \\
\hline None & 0.97 (0.49 to 1.94$)$ & 0.80 & $0.94(0.60$ to 1.46$)$ & 0.94 & 1.09 (0.91 to 1.30$)$ & 0.05 \\
\hline Primary & 1.15 (0.62 to 2.11$)$ & & 0.98 (0.65 to 1.50$)$ & & 0.91 (0.77 to 1.07$)$ & \\
\hline Secondary or higher & Reference & & Reference & & Reference & \\
\hline \multicolumn{7}{|l|}{ Wealth status } \\
\hline Poorest quintile & 0.76 (0.34 to 1.68$)$ & 0.89 & 0.86 (0.53 to 1.40$)$ & 0.68 & 1.30 (1.05 to 1.61$)$ & $<0.05$ \\
\hline Second quintile & 0.92 (0.43 to 1.95$)$ & & 0.99 (0.61 to 1.63$)$ & & 1.34 (1.09 to 1.64$)$ & \\
\hline Middle quintile & 0.97 (0.48 to 1.96$)$ & & 1.09 (0.70 to 1.72$)$ & & 1.12 (0.91 to 1.37$)$ & \\
\hline Fourth quintile & 1.15 (0.58 to 2.28$)$ & & 0.80 (0.48 to 1.32$)$ & & 1.12 (0.93 to 1.37$)$ & \\
\hline Richest quintile & Reference & & Reference & & Reference & \\
\hline \multicolumn{7}{|l|}{ Employment status } \\
\hline Currently working & 1.59 (0.99 to 2.56$)$ & 0.05 & 1.30 (0.96 to 1.75$)$ & 0.09 & 1.02 (0.87 to 1.19$)$ & 0.83 \\
\hline Not working & Reference & & Reference & & Reference & \\
\hline \multicolumn{7}{|l|}{ Area of residence } \\
\hline Urban & 1.10 (0.64 to 1.88$)$ & 0.72 & 1.14 (0.80 to 1.63$)$ & 0.46 & 1.09 (0.93 to 1.27$)$ & 0.28 \\
\hline Rural & Reference & & Reference & & Reference & \\
\hline \multicolumn{7}{|l|}{ Maternal BMI } \\
\hline Underweight & 0.58 (0.35 to 0.97$)$ & $<0.05$ & 0.70 (0.52 to 0.94$)$ & 0.05 & 1.19 (1.05 to 1.34$)$ & $<0.05$ \\
\hline Average & Reference & & Reference & & Reference & \\
\hline Overweight & 1.81 (0.90 to 3.65$)$ & & 1.36 (0.80 to 2.32$)$ & & 0.86 (0.70 to 1.07$)$ & \\
\hline Obese & 1.84 (0.59 to 5.67$)$ & & 1.23 (0.53 to 2.89$)$ & & 0.86 (0.60 to 1.23$)$ & \\
\hline \multicolumn{7}{|c|}{ Maternal desire of pregnancy } \\
\hline Yes & 1.09 (0.71 to 1.68$)$ & 0.68 & $1.13(0.84$ to 1.51$)$ & 0.43 & $0.92(0.81$ to 1.05$)$ & 0.22 \\
\hline No & Reference & & Reference & & Reference & \\
\hline \multicolumn{7}{|c|}{ Ever use of contraception } \\
\hline Yes & Reference & & Reference & & Reference & \\
\hline No & 2.20 (1.32 to 3.68$)$ & $<0.05$ & 1.89 (1.35 to 2.64$)$ & $<0.001$ & 1.23 (1.06 to 1.42$)$ & $<0.05$ \\
\hline \multicolumn{7}{|l|}{ No of ANC visits } \\
\hline None & 0.89 (0.29 to 2.73$)$ & 0.62 & 1.61 (0.74 to 3.48$)$ & 0.48 & 1.09 (0.84 to 1.42$)$ & 0.79 \\
\hline $1-3$ & 1.21 (0.61 to 2.37$)$ & & 1.16 (0.71 to 1.89$)$ & & 1.03 (0.86 to 1.23$)$ & \\
\hline$\geq 4$ & Reference & & Reference & & Reference & \\
\hline
\end{tabular}


Table 2 Continued

\begin{tabular}{|c|c|c|c|c|c|c|}
\hline \multirow[b]{2}{*}{ Predictors } & \multicolumn{2}{|c|}{$\begin{array}{l}\text { First-day neonatal mortality } \\
n=21382\end{array}$} & \multicolumn{2}{|c|}{$\begin{array}{l}\text { Early neonatal mortality } \\
\mathrm{n}=21382\end{array}$} & \multicolumn{2}{|l|}{$\begin{array}{l}\text { Small birth size } \\
n=11022\end{array}$} \\
\hline & aOR $(95 \% \mathrm{Cl})$ & $P$ value & aOR $(95 \% \mathrm{Cl})$ & $P$ value & aOR $(95 \% \mathrm{Cl})$ & $P$ value \\
\hline \multicolumn{7}{|l|}{ ANC by SBA } \\
\hline Yes & Reference & & Reference & & Reference & \\
\hline No & 1.01 (0.46 to 2.19$)$ & 0.99 & $0.78(0.43$ to 1.42$)$ & 0.42 & 1.05 (0.83 to 1.32$)$ & 0.70 \\
\hline \multicolumn{7}{|c|}{ History of any previous pregnancy loss } \\
\hline Yes & 1.31 (0.85 to 2.03$)$ & 0.22 & 1.27 (0.94 to 1.71$)$ & 0.12 & 1.04 (0.91 to 1.20$)$ & 0.53 \\
\hline No & Reference & & Reference & & Reference & \\
\hline \multicolumn{7}{|l|}{ Sex of infant } \\
\hline Male & 1.70 (1.09 to 2.64$)$ & $<0.05$ & $1.32(1.01$ to 1.73$)$ & $<0.05$ & 0.71 (0.63 to 0.80$)$ & $<0.001$ \\
\hline Female & Reference & & Reference & & Reference & \\
\hline \multicolumn{7}{|l|}{ Region } \\
\hline Barisal & $0.59(0.27$ to 1.30$)$ & $<0.05$ & $0.82(0.51$ to 1.30$)$ & $<0.05$ & 0.74 (0.59 to 0.92$)$ & $<0.001$ \\
\hline Chittagong & $0.34(0.16$ to 0.71$)$ & & 0.50 (0.32 to 0.77$)$ & & $1.16(0.97$ to 1.38$)$ & \\
\hline Khulna & $0.72(0.35$ to 1.50$)$ & & 0.91 (0.57 to 1.44$)$ & & 0.96 (0.79 to 1.17$)$ & \\
\hline Rajshahi & 1.12 (0.63 to 1.99$)$ & & 1.02 (0.68 to 1.53$)$ & & 0.73 (0.60 to 0.89$)$ & \\
\hline Rangpur & 0.68 (0.35 to 1.29$)$ & & 0.99 (0.66 to 1.51$)$ & & 0.81 (0.65 to 0.99$)$ & \\
\hline Sylhet & 0.83 (0.36 to 1.88$)$ & & 0.92 (0.53 to 1.61$)$ & & 1.24 (1.03 to 1.50$)$ & \\
\hline Dhaka & Reference & & Reference & & Reference & \\
\hline
\end{tabular}

*ORs were adjusted for maternal age at childbirth, birth order, maternal education, maternal wealth index, maternal employment status, area of residence, maternal BMI, maternal desire of pregnancy, ever use of contraceptive method, number of ANC visits, ANC by SBA, history of any previous pregnancy loss, sex of infant and region.

ANC, antenatal care; BDHS, Bangladesh Demographic and Health Surveys; BMI, body mass index; SBA, skilled birth attendants.

birth size and may be responsible for this non-association. However, the direction of the effect is consistent with several earlier investigations including a meta-analysis of 69 studies from both LMICs and high-income countries. ${ }^{6} 2124$

Several hypotheses have been proposed to explain the association between short birth intervals and adverse pregnancy outcomes. ${ }^{25}$ One of the most frequently used hypotheses is the maternal nutritional depletion phenomenon, which has been defined by Winkvist et al as a negative change in maternal nutritional status during a reproductive cycle, mostly due to the biological competition between mother and the growing fetus. ${ }^{26-28}$ Short birth spacing does not allow mothers sufficient time to restore nutritional reserves needed to support fetal growth and development during the subsequent pregnancy. This eventually causes maternal nutritional depletion that leads to the increase risk of adverse pregnancy outcomes among the births spaced after a short interval. Another explanation is that the association of short birth intervals and adverse pregnancy outcomes could be confounded by other factors including young maternal

Table 3 Results of multivariable analysis for the association between preceding birth intervals and adverse pregnancy outcomes by history of any previous pregnancy loss: BDHS 1996-2014

\begin{tabular}{|c|c|c|c|c|c|c|}
\hline \multirow[b]{2}{*}{ Predictors } & \multicolumn{2}{|c|}{$\begin{array}{l}\text { First-day neonatal mortality } \\
\mathrm{n}=21382\end{array}$} & \multicolumn{2}{|c|}{$\begin{array}{l}\text { Early neonatal mortality } \\
n=21382\end{array}$} & \multicolumn{2}{|l|}{$\begin{array}{l}\text { Small birth size } \\
n=11022\end{array}$} \\
\hline & aOR $(95 \% \mathrm{Cl})$ & $P$ value & aOR $(95 \% \mathrm{Cl})$ & $P$ value & aOR $(95 \% \mathrm{Cl})$ & P value \\
\hline \multicolumn{7}{|c|}{ Preceding birth interval in months ${ }^{\star}$ history of any previous pregnancy loss } \\
\hline$<36$ & $2.12(0.74$ to 6.13$)$ & 0.28 & 1.77 (0.90 to 3.49$)$ & 0.19 & 0.96 (0.69 to 1.33$)$ & 0.38 \\
\hline $36-59$ & Reference & & Reference & & Reference & \\
\hline$\geq 60$ & 2.15 (0.73 to 6.31$)$ & & 1.74 (0.84 to 3.62$)$ & & 1.18 (0.87 to 1.59$)$ & \\
\hline
\end{tabular}

${ }^{*}$ ORs were adjusted for maternal age at childbirth, birth order, maternal education, maternal wealth index, maternal employment status, area of residence, maternal BMI, maternal desire of pregnancy, ever use of contraceptive method, number of ANC visits, ANC by SBA, sex of infant and region.

ANC, antenatal care; BDHS, Bangladesh Demographic and Health Surveys; BMI, body mass index; SBA, skilled birth attendants. 
age, lower socioeconomic status and lower utilisation of health services. ${ }^{29}{ }^{30}$ In our analysis, after adjusting for maternal age, socioeconomic factors and maternal characteristics as well as health service-related factors, a short birth interval remained associated with first-day and early neonatal mortality which is in line with other studies from both LMICs and high-income countries that controlled for similar variables. ${ }^{14173132}$

Our study further identified the association of a long birth interval with adverse perinatal outcomes and found that infants born after a long birth interval were at greater odds of first-day neonatal mortality. The effect of long birth intervals on early neonatal mortality was also greater but was not significant. There are only a few published studies on the effect of a long birth interval on adverse pregnancy outcomes in LMICs and the results are conflicting. ${ }^{6} 2122$ In contrast to our findings, a previous investigation conducted in India, examined the effect of a long birth interval for perinatal death and did not find any association, ${ }^{21}$ and a pooled analysis of 47 DHS examined the effect of a longer birth interval for neonatal mortality and found that the odds were lower for the longer preceding birth intervals ( $\geq 60$ months) (OR: 0.80 , $95 \%$ CI: 0.67 to 0.95$)$ compared with the birth interval of 24 to $<60$ months. ${ }^{23}$ The inconsistency in findings could be attributed to methodological differences in both the reference category (36-59 vs 24 to $<60$ months) of the main exposure variable and the difference in the outcome variable (early neonatal mortality vs neonatal mortality). However, our findings are consistent with a meta-analysis which reported higher odds of early neonatal mortality with a longer interval, ${ }^{6}$ and Rutstein's study which analysed data from 17 LMICs. ${ }^{11}$ Again, we found that a long birth interval was associated with greater odds of small birth size, similar to a few prior studies which also suggested the detrimental effect of a long birth interval on birth size. ${ }^{62133}$

The increased odds of adverse pregnancy outcomes for long birth intervals may be due to concurrent factors such as advanced maternal age and previous history of pregnancy loss. In an earlier investigation, Zhu et al explained the association between long birth intervals and adverse pregnancy outcomes through the gradual decline in the maternal physiological and anatomical capacities of the reproductive system, hypothesising that if a woman does not conceive for an extended time after a delivery, her physiological characteristics may return to her unprepared primigravid state. ${ }^{34}$ Further research is needed to understand the relationship.

\section{Strengths and limitations}

The main strength of our study is that it was based on a large nationally representative sample from six surveys within an 18-year time period in a single country, which would improve the homogeneity of the data. We restricted our analysis to the most recent live births within the 5 years prior to the interview date to minimise recall bias.
Furthermore, we were able to add a number of potential confounding factors.

We acknowledge some methodological limitations. First, these are cross-sectional data, which may limit the identification of a causal relationship between the birth interval and adverse pregnancy outcomes. Second, BDHS data relies on maternal recall and report of the information regarding preceding birth intervals and the days of infant deaths, which are subject to recall bias. Third, there is a possibility of under-reporting of infant deaths, as birth histories and infant survival information were only collected from surviving mothers and there is a strong association between maternal and infant deaths. Fourth, we acknowledge a limitation of using maternal perception of infant birth size instead of infant birthweight in our analysis due to unavailability of actual estimates of birthweight in BDHS, which may reflect newborn's overall health status rather than birthweight only. Fifth, as we pooled six BDHS datasets over 18 years, there may be a possibility of changes in the background characteristics of the population over 18 years. Furthermore, in our analysis, we were unable to include the variable regarding the history of immediate previous adverse outcome such as stillbirth and miscarriage, which is a determinant of adverse perinatal outcomes in a subsequent pregnancy. A previous investigation conducted in Bangladesh using dynamic panel data models reported that a previous adverse birth outcome may be subject to a 'scarring effect', which leads to a short birth interval (replacement) and thus increases the risk of mortality of the subsequent infant (nutritional depletion); as a mother with a previous pregnancy loss may rush into a pregnancy without properly recovering from the pregnancy loss. ${ }^{35}$ In our analysis, we were unable to consider the role of 'scarring effect' related to a previous adverse pregnancy outcome which has an influence on birth interval. To account for this, we were able to stratify our analysis by the variable "ever had a pregnancy loss', although that stratification increased the effect sizes of first-day and early neonatal mortality for both short and long birth intervals, neither were significant.

\section{CONCLUSIONS}

Our analysis supports the reduced risk of adverse pregnancy outcomes following a birth-to-birth interval of 36-59 months, which is consistent with the WHO recommendation of a birth-to-pregnancy interval of 24 months. Our results highlight several important implications for care-providers, programme managers and policymakers by suggesting that a preceding birth interval of 36-59 months could prevent adverse pregnancy outcomes including first-day neonatal death, early neonatal death and low birthweight. Promoting an optimal birth interval of 36-59 months through postpartum family planning may reduce perinatal and neonatal mortality. 
Acknowledgements The authors would like to thank Sydney Medical School, The University of Sydney for funding MKN's PhD (Early Career Researcher Postgraduate Scholarship). The authors would also like to thank MEASURE DHS and NIPORT for permitting to analyse the BDHS 1996-2014 datasets.

Contributors MKN, CRG and AA conceptualised and designed the study. MKN performed the literature review. MKN, CRG, MTI and TH performed statistical analysis. MKN and CRG drafted the manuscript. MKN and CRG contributed to the interpretation of the data. MKN, CRG, AA and MTI contributed to the critical revision of the manuscript. All the authors read and approved the final manuscript.

Funding CRG is funded by the National Health and Medical Research Council Career Development Award \#1087062.

Competing interests None declared.

Patient consent for publication Not required.

Ethics approval Ethics approval was not required for our analyses, as the data were anonymous and publicly available.

Provenance and peer review Not commissioned; externally peer reviewed.

Data sharing statement The data are anonymous and publicly available in the website; www.measuredhs.com.

Open access This is an open access article distributed in accordance with the Creative Commons Attribution Non Commercial (CC BY-NC 4.0) license, which permits others to distribute, remix, adapt, build upon this work non-commercially, and license their derivative works on different terms, provided the original work is properly cited, appropriate credit is given, any changes made indicated, and the use is non-commercial. See: http://creativecommons.org/licenses/by-nc/4.0/.

\section{REFERENCES}

1. Blencowe $\mathrm{H}$, Cousens $\mathrm{S}$, Jassir FB, et al. National, regional, and worldwide estimates of stillbirth rates in 2015, with trends from 2000: a systematic analysis. Lancet Glob Health 2016;4:e98-e108.

2. Liu L, Oza S, Hogan D, et al. Global, regional, and national causes of child mortality in 2000-13, with projections to inform post-2015 priorities: an updated systematic analysis. The Lancet 2015;385:430-40.

3. World Health Organization. Newborns: reducing mortality. 2017 http://www.who.int/mediacentre/factsheets/fs333/en/ (Accessed 17 Nov 2017).

4. United Nations Children's Fund and World Health Organization. 2004. Low Birth Weight: Country, regional and global estimates: UNICEF, New York.

5. World Health Organization. Care of the preterm and low-birth-weight newborn. 2017. http://www.who.int/maternal_child_adolescent/ newborns/prematurity/en/ (12 Dec 2017).

6. Conde-Agudelo A, Rosas-Bermúdez A, Kafury-Goeta AC. Birth spacing and risk of adverse perinatal outcomes: a meta-analysis. JAMA 2006;295:1809-23.

7. Ekin A, Gezer C, Taner CE, et al. Impact of interpregnancy interval on the subsequent risk of adverse perinatal outcomes. J Obstet Gynaecol Res 2015;41:1744-51.

8. Qin C, Mi C, Xia A, et al. A first look at the effects of long interpregnancy interval and advanced maternal age on perinatal outcomes: A retrospective cohort study. Birth 2017;44:230-7.

9. World Health Organization. Report of a WHO Technical consultation on birth spacing. 2005.

10. Exavery A, Mrema S, Shamte A, et al. Levels and correlates of non-adherence to WHO recommended inter-birth intervals in Rufiji, Tanzania. BMC Pregnancy Childbirth 2012;12:152

11. Rutstein SO. Effects of preceding birth intervals on neonatal, infant and under-five years mortality and nutritional status in developing countries: evidence from the demographic and health surveys. Int $J$ Gynaecol Obstet 2005;89 Suppl 1:S7-S24.
12. National Institute of Population Research and Training (NIPORT) MaA, and ICF International. Bangladesh Demographic and Health Survey 2014. Dhaka, Bangladesh, and Rockville, Maryland, USA: NIPORT, Mitra and Associates, and ICF International, 2016.

13. Khan JR, Bari W, Latif AH. Trend of determinants of birth interval dynamics in Bangladesh. BMC Public Health 2016;16:934.

14. DaVanzo J, Hale L, Razzaque A, et al. The effects of pregnancy spacing on infant and child mortality in Matlab, Bangladesh: how they vary by the type of pregnancy outcome that began the interval. Popul Stud 2008;62:131-54.

15. de Jonge HC, Azad K, Seward N, et al. Determinants and consequences of short birth interval in rural Bangladesh: a crosssectional study. BMC Pregnancy Childbirth 2014;14:427.

16. Corsi DJ, Neuman M, Finlay JE, et al. Demographic and health surveys: a profile. Int J Epidemiol 2012;41:1602-13.

17. Rutstein SO. Further evidence of the effects of preceding birth intervals on neonatal, infant, and under-five-years mortality and nutritional status in developing countries: evidence from the demographic and health surveys. DHS Working Papers No 41. Calverton, Maryland, USA: Macro International, 2008.

18. Abir T, Agho KE, Page AN, et al. Risk factors for under-5 mortality: evidence from Bangladesh Demographic and Health Survey, 20042011. BMJ Open 2015;5:e006722.

19. Ezeh OK. Trends and population-attributable risk estimates for predictors of early neonatal mortality in Nigeria, 2003-2013: a crosssectional analysis. BMJ Open 2017;7:e013350.

20. Ghimire PR, Agho KE, Renzaho A, et al. Socio-economic predictors of stillbirths in Nepal (2001-2011). PLoS One 2017;12:e0181332.

21. Mahande MJ, Obure J. Effect of interpregnancy interval on adverse pregnancy outcomes in northern Tanzania: a registry-based retrospective cohort study. BMC Pregnancy Childbirth 2016;16:140.

22. Williams EK, Hossain MB, Sharma RK, et al. Birth interval and risk of stillbirth or neonatal death: findings from rural north India. $J$ Trop Pediatr 2008;54:321-7.

23. Kozuki N, Walker N. Exploring the association between short/long preceding birth intervals and child mortality: using reference birth interval children of the same mother as comparison. BMC Public Health 2013;13(Suppl 3):S6.

24. Appareddy S, Pryor J, Bailey B. Inter-pregnancy interval and adverse outcomes: Evidence for an additional risk in health disparate populations. J Matern Fetal Neonatal Med 2017;30:2640-4.

25. Miller JE. Birth intervals and perinatal health: an investigation of three hypotheses. Fam Plann Perspect 1991;23:62-70.

26. Winkvist A, Rasmussen KM, Habicht JP. A new definition of maternal depletion syndrome. Am J Public Health 1992;82:691-4.

27. King JC. The risk of maternal nutritional depletion and poor outcomes increases in early or closely spaced pregnancies. J Nutr 2003;133:1732S-6.

28. Smits LJ, Essed GG. Short interpregnancy intervals and unfavourable pregnancy outcome: role of folate depletion. Lancet 2001;358:2074-7.

29. Klebanoff MA. The interval between pregnancies and the outcome of subsequent births. N Engl J Med 1999;340:643-4.

30. Wendt A, Gibbs CM, Peters S, et al. Impact of increasing interpregnancy interval on maternal and infant health. Paediatr Perinat Epidemiol 2012;26(s1):239-58.

31. Conde-Agudelo A, Belizán JM, Norton MH, et al. Effect of the interpregnancy interval on perinatal outcomes in Latin America. Obstet Gynecol 2005;106:359-66.

32. Stamilio DM, DeFranco E, Paré E, et al. Short interpregnancy interval: risk of uterine rupture and complications of vaginal birth after cesarean delivery. Obstet Gynecol 2007;110:1075-82.

33. Zhu BP. Effect of interpregnancy interval on birth outcomes: findings from three recent US studies. Int J Gynaecol Obstet 2005;89:S25-33.

34. Zhu BP, Rolfs RT, Nangle BE, et al. Effect of the interval between pregnancies on perinatal outcomes. N Engl J Med 1999;340:589-94.

35. Saha UR, van Soest A. Infant death clustering in families: magnitude, causes, and the influence of better health services, Bangladesh 1982-2005. Popul Stud 2011;65:273-87. 